\title{
Organized Comprehensive Stroke Center is Associated with Reduced Mortality: Analysis of Consecutive Patients in a Single Hospital
}

\author{
Dae-Hyun Kim, ${ }^{\text {a,b }}$ Jae-Kwan Cha, ${ }^{\text {a,b }}$ Hyo-Jin Bae, ${ }^{\text {a,b }}$ Hyun-Seok Park, Jae-Hyung Choi, ${ }^{\text {b }}$

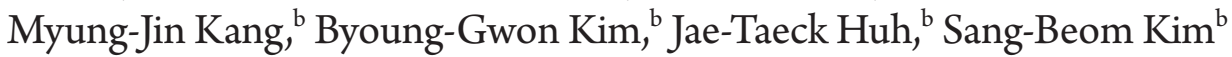 \\ ${ }^{a}$ Department of Neurology, Dong-A University College of Medicine, Busan; \\ bBusan-Ulsan Regional Cardiocerebrovascular Center, Busan, Korea
}

Background and Purpose Organized inpatient stroke care is one of the most effective therapies for improving patient outcomes. Many stroke centers have been established to meet this need, however, there are limited data on the effectiveness of these organized comprehensive stroke center (CSC) in the real-world setting. Our aim is to determine whether inpatient care following the establishment of CSC lowers mortality of patients with acute ischemic stroke (AIS).

Methods Based on a prospective stroke registry, we identified AIS patients hospitalized before and after the establishment of a CSC. We observed all-cause mortality within 30 days from time of admission. Logistic regression was used to determine whether the establishment of the CSC affects independently the 30-day all-cause mortality.

Results A total of 3,117 consecutive patients with AIS were admitted within seven days after the onset of the symptoms. Unadjusted 30-day mortality was lower for patients admitted to our hospital after the establishment of the CSC than before ( $5.9 \%$ vs. $8.2 \%, P=0.012$ ). Advanced age, female gender, previous coronary artery disease, non-smoking, stroke subtype, admission on a holiday, referral from other hospitals, high NIHSS on admission, and admission before the establishment of CSC were associated with increased 30-day stroke case fatality. After adjustment for these factors, stroke inpatient care subsequent to the establishment of the CSC was independently associated with lower 30-day mortality (OR, 0.57 ; 95\% Cl, 0.412-0.795).

Conclusions Patients treated after the establishment of a CSC had lower 30-mortality rates than ever before, even adjusting for the differences in the baseline characteristics. The present study reveals that organized stroke care in a CSC might improve the outcome after AIS.

Keywords Stroke center; Acute ischemic stroke; Stroke care organization; Stroke mortality

\author{
Correspondence: Jae-Kwan Cha \\ Department of Neurology, Dong-A \\ University College of Medicine, 32 \\ Daesingongwon-ro, Seo-gu, Busan \\ 602-714, Korea \\ Tel: $+82-51-240-5570$ \\ Fax: +82-51-244-8338 \\ E-mail:nrcjk65@gmail.com
}

Received: August 29, 2012

Revised: January 16, 2013

Accepted: January 24, 2013

This study was supported by Dong-A University Research Fund.

The authors have no financial conflicts of interest.

\section{Introduction}

Stroke is the leading cause of serious long-term disability and mortality in Korea. ${ }^{1}$ Organized treatment in stroke centers for patients with an acute stroke may reduce the mortality from this disorder. ${ }^{2,3}$ The Brain Attack Coalition categorized the types of stroke centers into primary and comprehensive, ${ }^{46}$ and outlined the recommendations for comprehensive stroke centers (CSC) ${ }^{6}$ 
Comprehensive stroke centers are designed to have the "necessary personnel, infrastructure, expertise, and programs to diagnose and treat stroke patients who require a high intensity of medical and surgical care, specialized tests, or interventional therapies."

Within the first 30 days after an ischemic stroke, the case fatality has been variously reported as $3.5-25 \%$ and the major causes of death were the index stroke and its sequelae. ${ }^{7-12}$ Thirtyday stroke case fatality has been used as a key indicator for hospital performance and quality of care to compare hospitals and to implement quality improvement strategies. ${ }^{8,13-15}$

Despite widespread establishment of CSCs in Korea, there is limited empirical evidence which demonstrates whether more organized stroke care at a stroke unit reduces stroke mortality. ${ }^{16,17}$ Therefore, our goal was to compare the 30-day mortality of patients with acute ischemic stroke (AIS) that were treated at our hospital during the 3 years before and the 3 years after the establishment of the CSC.

\section{Methods}

\section{Patients selection}

This study was based on our prospective stroke registry. All patients with AIS and transient ischemic attack admitted to our hospital within 7 days after the onset of symptoms, from January 2006 to present, have been enrolled. Stroke severity was assessed according to the National Institutes of Health Stroke Scale (NIHSS). ${ }^{18}$ Assessment was performed in the emergency room at the time of admission. After admission, all patients were evaluated using a protocol that included demographic data, medical history, and vascular risk factors. We divided the patients into 5 groups, using the TOAST criteria. ${ }^{19}$ Their clinical data were registered in the stroke registry by two trained study nurses.

We divided these enrolled patients into two groups corresponding to each of the three year intervals, before and after the establishment of the CSC. Patients with incomplete or missing clinical data, and transient ischemic attacks were excluded.

This study was approved by the Institutional Review Board at Dong-A University Hospital.

\section{Establishment of the comprehensive stroke center}

Our hospital is a tertiary teaching hospital located in the Busan metropolitan area. Our stroke center was opened in January 2009 through financial support from the Korean government. Before the establishment of CSC, neither a stroke team nor a stroke care unit was present at our hospital. At the same time as the CSC opened, a 6-bed stroke care unit was installed for care of the acute stroke patients, which had a telemetry system for the monitoring of blood pressure, pulse, respiration and oxygenation.

With establishment of the CSC, to shorten the processing time to within the time window of IV t-PA use, we applied a central alerting system to recruit all available stroke team members to the emergency room, as soon as possible, after the arrival of suspected stroke patients.

A multidisciplinary group developed stroke care pathways to guide the evaluation and treatment of each stroke subtype. Stroke treatment was generally administered according to a well-organized team approach, e.g., intravenous thrombolysis, endovascular treatment, hemicraniectomy and carotid endarterectomy.

After the establishment of the stroke center, several perfor-

Table 1. Components of CSC for ischemic stroke patient by a consensus statement from the Brain Attack Coalition ${ }^{6}$ and changes of each specific element according to before and after the establishment of our CSC

\begin{tabular}{|c|c|c|c|}
\hline & $\begin{array}{l}\text { Components } \\
\text { of CSC for } \\
\text { ischemic } \\
\text { stroke }^{6}\end{array}$ & $\begin{array}{l}\text { Before the } \\
\text { establishment } \\
\text { of CSC }\end{array}$ & $\begin{array}{c}\text { After the } \\
\text { establishment of CSC }\end{array}$ \\
\hline \multicolumn{4}{|l|}{ Personnel } \\
\hline Vascular neurologist & $\sqrt{ }$ & $\sqrt{ }$ & $\sqrt{ }$ \\
\hline Neurosurgeon & $\sqrt{ }$ & $\sqrt{ }$ & $\sqrt{ }$ \\
\hline Intensivist & As needed & & \\
\hline Vascular surgeon & $\sqrt{ }$ & & $\sqrt{ }(1)$ \\
\hline Endovascular specialist & $\sqrt{ }$ & $\sqrt{ }(1)$ & $\sqrt{ }(2)$ \\
\hline \multicolumn{4}{|l|}{ Care setting } \\
\hline Stroke unit & $\sqrt{ }$ & & $\sqrt{ }$ \\
\hline ICU & $\sqrt{ }$ & $\sqrt{ }$ & $\sqrt{ }$ \\
\hline \multicolumn{4}{|l|}{ Neuroimaging } \\
\hline MRI/MRA, DWI & $\sqrt{ }$ & $\sqrt{ }$ & $\begin{array}{c}\sqrt{ } \\
24 \text { hours per day, } \\
7 \text { days per week }\end{array}$ \\
\hline MRV & $\sqrt{ }$ & $\sqrt{ }$ & $\sqrt{ }$ \\
\hline Digital angiography & $\sqrt{ }$ & $\sqrt{ }$ & $\sqrt{ }$ \\
\hline Carotid ultrasound & $\sqrt{ }$ & $\sqrt{ }$ & $\sqrt{ }$ \\
\hline TCD & $\sqrt{ }$ & $\sqrt{ }$ & $\sqrt{ }$ \\
\hline TEE & $\sqrt{ }$ & $\sqrt{ }$ & $\sqrt{ }$ \\
\hline \multicolumn{4}{|l|}{ Endovascular therapy } \\
\hline Stent/angioplasty & $\sqrt{ }$ & $\sqrt{ }$ & $\sqrt{ }$ \\
\hline Reperfusion techniques & $\sqrt{ }$ & $\sqrt{ }$ & $\begin{array}{c}\sqrt{ } \\
24 \text { hours per day, } \\
7 \text { days per week }\end{array}$ \\
\hline \multicolumn{4}{|l|}{ Surgery } \\
\hline Ventriculostomy & $\sqrt{ }$ & $\sqrt{ }$ & $\sqrt{ }$ \\
\hline $\begin{array}{l}\text { Intracranial pressure } \\
\text { transducer }\end{array}$ & $\sqrt{ }$ & $\sqrt{ }$ & $\sqrt{ }$ \\
\hline Hemicraniectomy & $\sqrt{ }$ & $\sqrt{ }(14$ cases $)$ & $\sqrt{ }(53$ cases $)$ \\
\hline CEA & $\sqrt{ }$ & & $\sqrt{ }(47$ cases $)$ \\
\hline Brain biopsy & $\sqrt{ }$ & $\sqrt{ }$ & $\sqrt{ }$ \\
\hline
\end{tabular}

CSC, comprehensive stroke center; ICU, intensive care unit; MRI, magnetic resonance imaging; MRA, magnetic resonance angiography; DWI, diffusion-weighted imaging; MRV, magnetic resonance venography; TCD, transcranial Doppler; TEE, transesophageal echocardiography; CEA, carotid endarterectomy. 
mance measures improved as compared with beforehand. ${ }^{20}$ Care in our stroke center fulfilled the Brain Attack Coalition's standardized criteria (Table 1). ${ }^{6}$

\section{Clinical outcome measures}

We investigated the 30-day all-cause mortality of ischemic stroke patients for 3 years before and after the establishment of the CSC. Thirty-day case fatality was defined as the proportion of strokes for which death occurred within 30 days of stroke admission. Data on patients who were able to visit the outpatient department were captured. In all other cases, the survival or death at 1 month after the stroke was checked by a trained study nurse who undertook a standardized telephone interview with the patient or his or her next of kin. The survival or death was identified, regardless of cause of death.

\section{Statistical analysis}

Nominal variables were expressed as count and percentages, continuous values as the mean \pm standard deviation (SD). Ttest was used to analyze the difference in continuous variables, and the chi-square test for those in proportions. Non-normally distributed variables were compared using a Mann-Whitney $U$ test. We analyzed the influence of risk factors, clinical variables and the establishment of the CSC on 30-day mortality by a univariate analysis. We reanalyzed 30-day case fatality by means of logistic regression to evaluate whether the establishment of CSC is independently associated with reduced 30-day ischemic stroke mortality. The logistic regression model was applied with adjustment for the baseline variables that showed a $P$-value less than 0.1 on univariate analysis. In addition, propensity score matched analysis was performed to correct for bias. The results are presented as odds ratio (OR) estimates of relative risk with $95 \%$ confidence intervals $(\mathrm{CI})$. $P$-values $<0.05$ were considered statistically significant.

\section{Results}

During the study period, consecutive patients with AIS or transient ischemic attack $(n=3,339)$ were admitted to our hospital within seven days after the onset of the symptoms to our hospital. Patients with a diagnosis of transient ischemic attack ( $\mathrm{n}=$ $159)$ and those without 30-day outcome data $(n=63)$ were excluded. The proportion of the men among patients with 30-day follow-up loss was higher than the proportion of men in the included patients; age: $64.9 \pm 10.9$ vs. $65.5 \pm 12.3, P=0.720$, male: $74.6 \%$ vs. $62.2 \%, P=0.037$, NIHSS, median [ranges] : 5 [1-29] vs. $5[1-41], P=0.320$. Ultimately, we performed a retrospective study using a sample of 3,117 consecutive patients with AIS.
After a 6-bed stroke care unit was installed in the CSC, 86\% of AIS patients were admitted to the stroke care unit. The mean duration of hospitalization in stroke care unit was 3.5 days. Decompressive hemicraniectomies were performed in 14 patients for 3 years before the establishment of the CSC. After the establishment of the CSC, among 119 patients with malignant middle cerebral artery infarction, 53 patients (44.5\%) underwent decompressive hemicraniectomy. Forty patients with hemicraniectomy (75\%) survived for up to a month. Carotid endarterectomy was done in 47 patients with severe carotid artery stenosis (Table 1).

The baseline characteristics of ischemic stroke patients, before and after the implementation of the CSC, are presented in Table 2. Patients' mean age was 65.5 years, and $62.2 \%$ were men.

Among the 3,117 patients, $61.8 \%$ were treated at our hospital during the 3 -year period after opening of the CSC. These patients were older, and had lower frequencies of hypertension and current smoking behavior, and had more prior coronary artery disease and higher NIHSS scores on admission than those admitted before the CSC opened. Overall 30-day mortality was $6.8 \%$. The overall 30 -day all-cause mortality rate was $8.2 \%$ for patients admitted to our hospital before the establishment of CSCs and 5.9\% for patients admitted after (unadjusted mortality difference, $-2.3 \% ; P=0.012$ ).

Table 2. Characteristics of stroke patients according to before and after the establishment of comprehensive stroke center

\begin{tabular}{|c|c|c|c|c|}
\hline & $\begin{array}{c}\text { Total } \\
(n=3,117)\end{array}$ & $\begin{array}{l}\text { Admission } \\
\text { before CSC } \\
(n=1,190)\end{array}$ & $\begin{array}{l}\text { Admission } \\
\text { after CSC } \\
(n=1,927)\end{array}$ & $P$-value \\
\hline Age, years & $65.5 \pm 12.3$ & $64.3 \pm 12.2$ & $66.2 \pm 12.3$ & $<0.0001$ \\
\hline Male sex, $\mathrm{n}(\%)$ & $1,938(62.2)$ & $741(62.3)$ & $1,197(62.1)$ & 0.932 \\
\hline Hypertension, $\mathrm{n}(\%)$ & $1,766(56.7)$ & $758(63.7)$ & $1,008(52.3)$ & $<0.001$ \\
\hline Diabetes, n (\%) & $807(25.9)$ & $329(27.6)$ & $478(24.8)$ & 0.078 \\
\hline Previous stroke, $\mathrm{n}(\%)$ & $387(12.4)$ & $160(13.4)$ & $227(11.8)$ & 0.171 \\
\hline Previous CAD, n (\%) & $286(9.2)$ & $87(7.3)$ & $199(10.3)$ & $<0.005$ \\
\hline Currrent smoking, $\mathrm{n}(\%)$ & $844(27.1)$ & $417(35)$ & $427(22.2)$ & $<0.001$ \\
\hline Stroke subtypes & & & & 0.002 \\
\hline el disease & $701(22.5)$ & $261(21.9)$ & $440(22.8)$ & \\
\hline Cardiac embolism & $732(23.5)$ & $255(21.4)$ & $477(24.8)$ & \\
\hline Large artery disease & $1,119(35.9)$ & $441(37.1)$ & $678(35.2)$ & \\
\hline Others & $100(3.2)$ & $55(4.6)$ & & \\
\hline Undetermined & $465(14.9)$ & $178(15)$ & $287(14.9)$ & \\
\hline Admission on holiday, $\mathrm{n}(\%)$ & $902(28.9)$ & $340(28.6)$ & $562(29.2)$ & 0.723 \\
\hline Referral from other hospital, $\mathrm{n}(\%)$ & ) $1,535(49.3)$ & $568(47.9)$ & $967(50.2)$ & 0.210 \\
\hline NIHSS score, median (ranges) & $5(1-41)$ & $6(1-36)$ & $5(1-41)$ & $<0.001$ \\
\hline Stroke severity stratification & & & & 0.001 \\
\hline Mild (0-5) & $1,670(53.6)$ & $587(49.3)$ & $1,083(56.2)$ & \\
\hline Moderate (6-13) & $882(28.3)$ & $372(31.3)$ & $510(26.5)$ & \\
\hline Severe $(\geq 14)$ & $565(18.1)$ & $231(19.4)$ & $334(17.3)$ & \\
\hline Mortality on 30 days, $n(\%)$ & $212(6.8)$ & $98(8.2)$ & $114(5.9)$ & 0.012 \\
\hline
\end{tabular}

CSC, comprehensive stroke center; CAD, coronary artery disease; NIHSS, National Institutes of Health Stroke Scale. 
Table 3. Characteristics and vascular risk factors associated with 30-day stroke fatality

\begin{tabular}{|c|c|c|c|c|}
\hline & $\begin{array}{l}\text { Total cases } \\
(n=3,117)\end{array}$ & $\begin{array}{c}\text { Death with- } \\
\text { in } 30 \text { days } \\
(n=212)\end{array}$ & $\begin{array}{l}\text { Survival with- } \\
\text { in } 30 \text { days } \\
(n=2,905)\end{array}$ & $\begin{array}{c}P_{-} \\
\text {values }\end{array}$ \\
\hline Age, years & $65.5 \pm 12.3$ & $72.2 \pm 11.5$ & $64.9 \pm 12.2$ & $<0.001$ \\
\hline Male sex, n (\%) & $1,938(62.2)$ & ) 107 (50.5) & $1,831(63.0)$ & $<0.001$ \\
\hline Hypertension, $\mathrm{n}(\%)$ & $1,766(56.7)$ & ) $119(56.1)$ & $1,647(56.7)$ & 0.873 \\
\hline Diabetes, n (\%) & $807(25.9)$ & $55(25.9)$ & $752(25.9)$ & 0.985 \\
\hline Previous stroke, n (\%) & $387(12.4)$ & $25(11.8)$ & $362(12.5)$ & 0.776 \\
\hline Previous CAD, $\mathrm{n}(\%)$ & $286(9.2)$ & $33(15.6)$ & $253(8.7)$ & 0.001 \\
\hline Current smoking, n (\%) & $844(27.1)$ & $37(17.5)$ & $807(27.8)$ & 0.001 \\
\hline Stroke subtypes & & & & $<0.001$ \\
\hline Small vessel disease & $701(22.5)$ & $5(2.4)$ & $696(24)$ & \\
\hline Cardiac embolism & $732(23.5)$ & ) $91(42.9)$ & & \\
\hline Large artery disease & $1,119(35.9)$ & $69(32.5)$ & $1,050(36.1)$ & \\
\hline Others & $100(3.2)$ & $7(3.3)$ & & \\
\hline Undetermined & $465(14.9)$ & $40(18.9)$ & $425(14.6)$ & \\
\hline Admission on holiday, $\mathrm{n}(\%)$ & $902(28.9)$ & $85(40.1)$ & $817(28.1)$ & $<0.001$ \\
\hline Referral from other hospital, n & ) 1,535 (49.3) & $144(67.9)$ & 1,391 (47.8) & $<0.001$ \\
\hline NIHSS score, median (ranges) & $5(1-41)$ & $17(2-36)$ & $4(1-41)$ & $<0.001$ \\
\hline Stroke severity stratification & & & & $<0.001$ \\
\hline Mild (0-5) & $1,670(53.6)$ & $12(5.7)$ & $1,658(57.1)$ & \\
\hline Moderate (6-13) & $882(28.3)$ & $54(25.5)$ & $828(28.5)$ & \\
\hline Severe $(\geq 14)$ & $565(18.1)$ & 146 (68.9) & $419(14.4)$ & \\
\hline $\begin{array}{l}\text { Admission after the } \\
\text { establishment of CSC, } \mathrm{n}(\%)\end{array}$ & $1,927(61.8)$ & 114 (53.8) & $1,813(62.4)$ & 0.012 \\
\hline
\end{tabular}

CAD, coronary artery disease; NIHSS, National Institutes of Health Stroke Scale; CSC, comprehensive stroke center.

The characteristics of those patients who died in the first 30 days, compared with those who were alive, are shown in Table 3. On the unadjusted analysis, advanced age, female gender, previous coronary artery disease, no current smoking, stroke subtype, admission on a holiday, referral from other hospitals, higher NIHSS score on admission, and admission before the establishment of CSC were associated with higher 30-day stroke case fatality.

Logistic regression analysis was performed to further evaluate the independent predictor for 30-day mortality (Table 4). After a risk adjustment, the establishment of the CSC was independently associated with lower 30-day mortality (OR, 0.57 ; 95\% CI, 0.412-0.795, $P=0.001$ ).

Then, we performed one-to-one matching based on propensity scores of each patient. The propensity score matching procedure generated a matched cohort in which the baseline prognostic variables were balanced. The 30-day case-fatality in patients admitted to our hospital after opening the CSC was lower than prior to opening (OR 0.64, 95\% CI 0.458-0.955, $P=0.011$ ). (Supplementary Tables 1-2).

Although reductions in the odds of death at 30-day by logistic regression analysis was relatively high comparing with that by propensity score matching analysis, both were all statistically
Table 4. Multivariate analysis for 30-day stroke case fatality

\begin{tabular}{lcc}
\hline Variable & $P$-value & OR (95\% CI) \\
\hline Age & $<0.001$ & $1.04(1.026-1.058)$ \\
Male & 0.611 & $0.92(0.648-1.290)$ \\
Previous CAD & 0.042 & $1.61(1.018-2.543)$ \\
Current smoking & 0.248 & $0.77(0.497-1.198)$ \\
NIHSS & $<0.001$ & $1.19(1.159-1.217)$ \\
TOAST classification & & \\
$\quad$ Small vessel disease & 1 & 1 \\
Cardiac embolism & 0.01 & $3.49(1.350-9.010)$ \\
Large artery disease & 0.026 & $2.92(1.136-7.493)$ \\
$\quad$ Others & 0.08 & $3.09(0.873-10.933)$ \\
$\quad$ Undetermined & 0.001 & $4.85(1.829-12.835)$ \\
Admission on holiday & 0.085 & $1.33(0.961-1.846)$ \\
Referral from other hospital & 0.044 & $1.41(1.009-1.979)$ \\
Admission in CSC & 0.001 & $0.57(0.412-0.795)$
\end{tabular}

CAD, coronary artery disease; CSC, comprehensive stroke center.

significant. Thus, it was presumed that consistent results from two analytical methods were derived.

\section{Discussion}

This study showed that 30-day mortality rate of patients with AIS treated after the establishment of the CSC was lower than prior. This was true also after the adjustment for the differences in the baseline characteristics. These findings highlight the need for more organized comprehensive care for AIS patients to improve the stroke outcome.

Incidence of case fatality within 30 days of ischemic stroke in our hospital (6.8\%) was below the range $10 \%$ to $25 \%$ reported in previous hospital-based studies. ${ }^{7-11}$ However, the 30 -day mortality of our hospital was higher than that of a nationwide Korean study. ${ }^{12}$ This variation may be due to age, sex, race, quality of inpatient stroke care, risk factors and stroke severity among study subjects. For example, in our study, patients with cardiac embolism, large artery disease and undetermined cause of stroke are $3.49,2.92$, and 4.85 times more likely, respectively, to be dead 30 days after ischemic stroke than patients with a small vessel stroke. This is in accordance with the previous study reporting that patients with cardioembolic stroke had worse 30day survival than patients with non-cardioembolic stroke. ${ }^{9,21}$ The proportion of patients with cardioembolic stroke in our study (23.5\%) was higher than that that of a nationwide study in Korea (13.2-20.5\%). Also, our cohort includes approximately $50 \%$ of patients with referral from other hospitals who would be expected to have more severe neurological and medical complication precipitating the transfer. In our study and others, ${ }^{7,8}$ initial stroke severity was the most important predictor of mortality after stroke. However, in the administrative records of some 
of the previous studies, stroke severity was not taken into account. $^{7-12}$ Thus, we could not compare the neurological severity of stroke symptoms and medical cormorbidity with all other studies.

So far, thrombolysis, hemicraniectomy for malignant infarction, and stroke unit care are evidence-based therapies for ischemic stroke that achieve a substantial and long-lasting effect on neurological outcome..$^{22} \mathrm{~A}$ CSC can provide these treatments to patients with severe stroke, and patients with AIS who required specialized treatments, including endovascular treatment, decompressive surgery and carotid surgery. ${ }^{6}$ We can not determine which individual components of the Brain Attack Coalition criteria for stroke center recommendation were the most important contributors for the lower mortality observed in this study.

One of the most important components of organized treatment for patients with AIS is admission to a stroke unit with a continuous telemetry monitoring system and stroke-directed nursing. ${ }^{23}$ Stroke patients who received organized inpatient care in a stroke unit had better outcomes and reduced stroke fatality than those with stroke care in the general ward. ${ }^{23-25}$ Randomized trials have shown that stroke unit care prevents 1 death for 33 patients treated. ${ }^{23}$ According to 25 reports which compared stroke unit care with general wards, stroke unit care showed reductions in the odds of death recorded within 1 year of stroke follow-up (OR: 0.79; 95\% CI: 0.73 to $0.86 ; P=0.00001) .{ }^{26} \mathrm{In}$ addition, one Korean hospital study reported stroke unit care could reduce 3-month fatality rates by up to $80 \% .{ }^{16}$ There was no difference in group-specific mortality reduction according to the severity of stroke symptoms in our study. This is consistent with the findings that stroke units and organized inpatient care reduce 30-day death or institutionalization with the same magnitude of effect across all age groups ${ }^{27}$ and stroke subtypes. ${ }^{28}$

Fifty-three patients with malignant middle cerebral artery infarction underwent decompressive hemicraniectomy after the establishment of the CSC. Our results showed an 3.8- fold increase in the number of patients who underwent hemicraniectomy surgery after opening the CSC. Decompressive surgery in patients with malignant cerebral infarction increases the probability of survival from $28 \%$ to nearly $80 \%{ }^{29}$

Therefore, it is possible that improved guideline-based treatment, organized care in a stroke unit and decompressive hemicraniectomy may contribute to the lower mortality rates among the stroke patients that were treated in our hospital since the establishment of CSC.

Previous studies reported that inpatient stroke center care was associated with a lower mortality compared with general or non-certified hospitals care. ${ }^{2,3,30,31}$ According to the Registry of the Canadian Stroke Network, stroke unit and organized inpatient care could reduce stroke death at 30 days, indicating a result similar to our study. ${ }^{27}$ However, not all stroke patients have practical access to optimal care, often because of lack in facilities. In Europe, only few acute stroke patients are treated in appropriate centers. ${ }^{32}$

Our study also has several limitations. First, our study included patients admitted to a single Korean CSC, and the results can not necessarily be generalized to those treated in other facilities. Second, our CSC had not yet been certified within a professional accreditation scheme, such as the Joint Commission Primary Stroke Center, because there are currently no certification regulations for stroke centers in Korea. However, our stroke center did fulfill the standardized criteria for CSC that the Brain Attack Coalition had published. ${ }^{6}$ Third, because of the limitation of data collection, we could not obtain acute complication and recurrence rates data, both of which could have influenced some results. Last, our study focused on short-term mortality and could not consider other important patient outcomes, such as 90-day or 1-year functional status or the quality of life.

In summary, the present study reveals that more organized stroke care in our stroke center could successfully lower the 30day mortality rate. Organized stroke care in a CSC might improve the patient outcome after AIS.

\section{References}

1. Korea National Statistical Office. Annual Report on the Cause of Death Statistics 2008.

2. Xian Y, Holloway RG, Chan PS, Noyes K, Shah MN, Ting HH, et al. Association between stroke center hospitalization for acute ischemic stroke and mortality. JAMA 2011;305:373-380.

3. Meretoja A, Roine RO, Kaste M, Linna M, Roine S, Juntunen $M$, et al. Effectiveness of primary and comprehensive stroke centers: PERFECT Stroke: A nationwide observational study from Finland. Stroke 2011;41:1102-1107.

4. Alberts MJ, Hademenos G, Latchaw RE, Jagoda A, Marler JR, Mayberg MR, et al. Recommendations for the establishment of primary stroke centers. Brain attack coalition. JAMA 2000; 283:3102-3109.

5. Alberts MJ, Latchaw RE, Jagoda A, Wechsler LR, Crocco T, George MG, et al. Revised and updated recommendations for the establishment of primary stroke centers: a summary statement from the brain attack coalition. Stroke 2011;42:26512665.

6. Alberts MJ, Latchaw RE, Selman WR, Shephard T, Hadley MN, Brass LM, et al. Recommendations for comprehensive stroke centers: a consensus statement from the brain attack co- 
alition. Stroke 2005;36:1597-1616

7. Hankey GJ. Long-term outcome after ischaemic stroke/transient ischaemic attack. Cerebrovasc Dis 2003;16:14-19.

8. Saposnik G, Hill MD, O’Donnell M, Fang J, Hachinski V, Kapral MK. Variables associated with 7-day, 30-day, and 1-year fatality after ischemic stroke. Stroke 2008;39:2318-2324.

9. de Jong G, van Raak L, Kessels F, Lodder J. Stroke subtype and mortality. A follow-up study in 998 patients with a first cerebral infarct. J Clin Epidemiol 2003;56:262-268.

10. Turaj W, Slowik A, Dziedzic T, Pulyk R, Adamski M, Strojny J, et al. Increased plasma fibrinogen predicts one-year mortality in patients with acute ischemic stroke. J Neurol Sci 2006;246: 13-19.

11. Saposnik G, Fang J, O’Donnell M, Hachinski V, Kapral MK, Hill MD. Escalating levels of access to in-hospital care and stroke mortality. Stroke 2008;39:2522-2530.

12. Jung KH, Lee SH, Kim BJ, Yu KH, Hong KS, Lee BC, et al. Secular trends in ischemic stroke characteristics in a rapidly developed country: Results from the Korean Stroke Registry Study (Secular trends in Korean stroke). Circ Cardiovasc Qual Outcomes 2012;5:327-334.

13. Donabedian A. The quality of care. How can it be assessed? JAMA 1988;260:1743-1748.

14. Lavados PM, Sacks C, Prina L, Escobar A, Tossi C, Araya F, et al. Incidence, 30-day case-fatality rate, and prognosis of stroke in Iquique, Chile: a 2-year community-based prospective study (PISCIS project). Lancet 2005;365:2206-2215.

15. Smith MA, Liou JI, Frytak JR, Finch MD. 30-day survival and rehospitalization for stroke patients according to physician specialty. Cerebrovasc Dis 2006;22:21-26.

16. Ko YC, Han MK, Kim WJ, Kwon OK, Oh CW, Jung CK, et al. Differences of mortality and dependence between stroke unit and general ward care in acute ischemic stroke patients. J Korean Neurol Assoc 2009;27:116-122.

17. Kim SH, Park CH, Han SW, Lee BI, Heo JH, Yonsei stroke team. Clinical usefulness of stroke unit: the comparison of inhospital treatment outcomes between stroke unit and general ward cares. Korean J Stroke 2004;6:145-150.

18. Goldstein LB, Samsa GP. Reliability of the national institutes of health stroke scale. Extension to non-neurologists in the context of a clinical trial. Stroke 1997;28:307-310.

19. Adams H, Jr, Bendixen BH, Kappelle LJ, Biller J, Love BB, Gordon DL, et al. Classification of subtype of acute ischemic stroke. Definitions for use in a multicenter clinical trial. Toast. Trial of org 10172 in acute stroke treatment. Stroke 1993;24: 35-41.
20. Bae HJ, Kim DH, Yoo NT, Choi JH, Huh JT, Cha JK, et al. Prehospital notification from the emergency medical service reduces the transfer and intra-hospital processing times for acute stroke patients. J Clin Neurol 2010;6:138-142.

21. Petty GW, Brown RD Jr, Whisnant JP, Sicks JD, O’Fallon WM, Wiebers DO. Ischemic stroke subtypes: a population-based study of functional outcome, survival, and recurrence. Stroke 2000;31:1062-1068.

22. The European Stroke Organisation (ESO) Executive Committee ESO Writing Committee. Guidelines for Management of Ischaemic Stroke and Transient Ischaemic Attack 2008. Cerebrovasc Dis 2008;25:457-507.

23. Stroke unit trialists' collaboration. Organised inpatient (stroke unit) care for stroke. Cochrane Database Syst Rev 2007;1:CD 000197.

24. Stroke unit trialists' collaboration. Collaborative systematic review of the randomised trials of organised inpatient (stroke unit) care after stroke. BMJ 1997;314:1151-1159.

25. Govan L, Weir CJ, Langhorne P. Organized inpatient (stroke unit) care for stroke. Stroke 2008;39:2402-2403.

26. Seenan P, Long M, Langhorne P. Stroke units in their natural habitat: Systematic review of observational studies. Stroke 2007; 38:1886-1892.

27. Saposnik G, Kapral MK, Coutts SB, Fang J, Demchuk AM, $\mathrm{Hill} \mathrm{MD}$, et al. Do all age groups benefit from organized inpatient stroke care? Stroke 2009;40:3321-3327.

28. Smith EE, Hassan KA, Fang J, Selchen D, Kapral MK, Saposnik $\mathrm{G}$, et al. Do all ischemic stroke subtypes benefit from organized inpatient stroke care? Neurology 2010;75:456-462.

29. Vahedi K, Hofmeijer J, Juettler E, Vicaut E, George B, Algra A, et al. Early decompressive surgery in malignant infarction of the middle cerebral artery: a pooled analysis of three randomised controlled trials. Lancet Neurology 2007;6:215-222.

30. Lichtman JH, Jones SB, Wang Y, Watanabe E, Leifheit-Limson E, Goldstein LB. Outcomes after ischemic stroke for hospitals with and without Joint Commission-certified primary stroke centers. Neurology 2011;76:1976-1982.

31. Lichtman JH, Allen NB, Wang Y, Watanabe E, Jones SB, Goldstein LB. Stroke patient outcomes in us hospitals before the start of the Joint Commission primary stroke center certification program. Stroke 2009;40:3574-3579.

32. Leys D, Ringelstein EB, Kaste M, Hacke W. Facilities available in European hospitals treating stroke patients. Stroke 2007;38: 2985-2991. 
Supplementary Table 1. Characteristics of stroke inpatients before the establishment of comprehensive stroke center and propensity-matched controls

\begin{tabular}{|c|c|c|c|c|}
\hline & $\begin{array}{c}\text { Total } \\
(\mathrm{n}=2,166)\end{array}$ & $\begin{array}{c}\text { Admission } \\
\text { before CSC } \\
(n=1,083)\end{array}$ & $\begin{array}{l}\text { Admission } \\
\text { after CSC } \\
(n=1,083)\end{array}$ & $\begin{array}{c}P- \\
\text { value }\end{array}$ \\
\hline Age, years & $64.86 \pm 12.17$ & $64.93 \pm 12.05$ & $64.78 \pm 12.30$ & 0.778 \\
\hline Male sex, $\mathrm{n}(\%)$ & $1,320(60.9)$ & $667(61.6)$ & $653(60.3)$ & 0.538 \\
\hline Hypertension, $\mathrm{n}(\%)$ & $1,325(61.2)$ & $666(61.5)$ & $659(60.9)$ & 0.102 \\
\hline Diabetes, $\mathrm{n}(\%)$ & $584(27.0)$ & $300(27.7)$ & $284(26.2)$ & 0.758 \\
\hline Previous stroke, $\mathrm{n}(\%)$ & $281(13.0)$ & $153(14.1)$ & $128(11.8)$ & 0.439 \\
\hline Previous CAD, $n(\%)$ & $145(6.7)$ & $82(7.6)$ & $63(5.8)$ & 0.110 \\
\hline Currrent smoking, $\mathrm{n}(\%)$ & $654(30.2)$ & $336(31.0)$ & $318(29.4)$ & 0.400 \\
\hline Stroke subtypes & & & & 0.958 \\
\hline Small vessel disease & $448(20.7)$ & $221(20.4)$ & $227(21.0)$ & \\
\hline Cardiac embolism & $481(22.2)$ & $238(22.0)$ & $243(22.4)$ & \\
\hline Large artery disease & $993(45.8)$ & $501(46.3)$ & $492(45.4)$ & \\
\hline Others & $74(3.4)$ & & $39(3.6)$ & \\
\hline Undetermined & $170(7.9)$ & $88(8.1)$ & $82(7.6)$ & \\
\hline Admission on holiday, n (\%) & $641(29.6)$ & $311(28.7)$ & $330(30.5)$ & 0.371 \\
\hline $\begin{array}{l}\text { Referral from other hospital, } \\
\mathrm{n}(\%)\end{array}$ & $1,038(47.9)$ & $526(48.6)$ & $512(47.3)$ & 0.547 \\
\hline NIHSS score, median (ranges) & $5(0-36)$ & $5(0-36)$ & $5(0-32)$ & 0.885 \\
\hline Stroke severity stratification & & & & 0.976 \\
\hline Mild (0-5) & $1,107(51.1)$ & $552(51.0)$ & $555(51.3)$ & \\
\hline Moderate (6-13) & $655(30.2)$ & 327 (30.2) & $328(30.3)$ & \\
\hline Severe $(\geq 14)$ & 404 (18.7) & 204 (18.8) & 200 (18.5) & \\
\hline
\end{tabular}

CSC, comprehensive stroke center; CAD, coronary artery disease; NIHSS, National Institutes of Health Stroke Scale.
Supplementary Table 2. Distribution of the number of patients and death at 30 days according to before and after the establishment of comprehensive stroke center

\begin{tabular}{lccc}
\hline & $\begin{array}{c}\text { Admission before } \\
\operatorname{CSC}(n=1,083)\end{array}$ & $\begin{array}{c}\text { Admission after } \\
\operatorname{CSC}(n=1,083)\end{array}$ & $P$-value \\
\hline Alive at 30 days, $n(\%)$ & $994(91.8)$ & $1,024(94.6)$ & 0.011 \\
Death at 30 days, $n(\%)$ & $89(8.2)$ & $59(5.4)$ & \\
\hline
\end{tabular}

CSC, comprehensive stroke center. 